\title{
A responsabilidade civil ambiental pelos resíduos sólidos oriundos dos serviços de saúde
}

\section{Environmental civil liability for the solid waste from health} service

La responsabilidad civil ambiental por los residuos sólidos procedentes de los servicios de salud

Paula Thays Schaiblich Moura ${ }^{1}$ Danila Fernanda Rodrigues Frias ${ }^{2}$

${ }^{1}$ Mestre em Ciências Ambientais. Especialista em Direito Público. Graduada em Direito pela Pontifícia Universidade Católica de Goiás (PUC-GO). Advogada e Assessora Jurídica da Prefeitura Municipal de Prata, MG.

E-mail: paulathays18@hotmail.com, Orcid: http://orcid.org/0000-0003-3145-4278

${ }^{2}$ Doutor e mestre em Medicina Veterinária pela Universidade Estadual Paulista Júlio de Mesquita Filho (UNESP). Graduado em Medicina Veterinária pela Universidade Brasil. Professor titular na Universidade Brasil, com experiência na área de Medicina Veterinária, com ênfase em Medicina Veterinária Preventiva. E-mail: danila.frias@universidadebrasil.edu.br, Orcid: http://orcid.org/0000-0001-8621-3338 
Resumo: Os resíduos, na sua imensa diversidade, não podem ser dispostos sem prévio tratamento. O objetivo deste estudo foi demonstrar a necessidade de responsabilização civil dos entes produtores de resíduos de serviço de saúde. Foram analisadas as Leis Municipais, os processos licitatórios e avaliação no Plano de Gerenciamento de Resíduos Sólidos (PGRSS) do Município de Prata, MG. Foi desenvolvido um Termo de Referência para compor o processo licitatório de seleção de empresas para realização de limpeza pública, e um texto referente à alteração na legislação municipal. Constatou-se a necessidade de praticar educação ambiental no sentido de auxiliar as pessoas atuantes na área da saúde no gerenciamento dos resíduos, além disso, o PGRSS apresenta falhas, pois não regulamenta a responsabilidade e aplicação de penas. Com a conclusão deste trabalho foi possível notar a importância de adequação do PGRSS das unidades de saúde públicas e privadas para dar efetividade às normas legais.

Palavras-chave: educação ambiental; legislação municipal; plano de gerenciamento de resíduos de serviço de saúde.

\begin{abstract}
In its huge diversity, the waste, can't be exposed without treatment. The aim of this study was to display the necessity of the civil liability of the producer entities of waste from health service. It was analysis Municipal Laws, the bidding processes, and evaluation in the Municipal Management Plan of Solid Waste (MPSW) in the municipality of Prata. It was developed a Term of Reference to make up the bidding process, and a text refering to the alteration in the local legislation. Verify the need of practicing environmental education in the sense of helping to the management of the waste. Besides that, the PGRSS has failures because it doesn't regulate the responsability and the application of penalties. By concluding this search it was possible to observe the importance of the adequacy of the MPSW refering to the public and private health unities to make the legal norms.
\end{abstract}

Keyworld: environmental education; municipal legislation; health service waste management plan.

Resumen: En su inmensa diversidad, los residuos, no pueden ser expuestos sin tratamiento. El objetivo de este estudio fue demostrar la necesidad de responsabilización civil de los entes productores de residuos de servicio de salud. Se analizaron las Leyes Municipales, los procesos licitatorios y evaluación en el Plan de Gestión de Residuos Sólidos (PGRSS) del Municipio de Plata. Se desarrolló un Término de Referencia para componer el proceso licitatorio y un texto referente a alteración en la legislación municipal. Se constató la necesidad de practicar educación ambiental en el sentido de auxiliar en la gestión de los residuos, además, el PGRSS tiene fallas pues no reglamenta la responsabilidad y aplicación de plumas. Con la conclusión de esta investigación fue posible notar la importancia de adecuación del PGRSS de las unidades de salud públicas y privadas para dar efectividad a las normas legales.

Palabras clave: educación ambiental; legislación municipal; plan de gestión de residuos de servicio de salud 


\section{INTRODUÇÃO}

É certo que a sociedade atual está cada vez mais preocupada com as questões ambientais. A mídia nos traz diariamente termos como desenvolvimento sustentável, ecologia, entre outros assuntos inerentes ao meio ambiente. Assim é notório que a conservação ambiental está se tornando prioridade, desde o início do estudo primário.

Na sua imensa diversidade, os resíduos, qualquer que seja sua classificação, não podem ser dispostos na natureza sem tratamento ou mesmo destinação correta. E os resíduos produzidos nas áreas de serviços em saúde necessitam de uma coleta especial, de forma que todos os riscos de contaminação sejam eliminados até a sua destinação final. Ressalta-se que, quando se fala em serviços de saúde, entendem-se como fontes geradoras os resíduos dos hospitais, clínicas, laboratórios, consultórios e outros.

Para minimizar o impacto ambiental causado por esse problema, é extremamente necessária à implantação de tecnologias eficientes e a submissão desses resíduos a tratamento correto, elaborando parâmetros para gerir esses materiais de forma adequada.

O Plano de Gerenciamento de Resíduos de Serviços de Saúde visa estipular regras para um manejo seguro, visando proteger tanto os profissionais quanto o meio ambiente.

Dessa forma, foram criadas regras de planejamento e gerenciamento dos resíduos, como seu manejo, armazenamento, identificação, tratamento, coleta, transporte externo e por fim sua destinação final. Tudo isto na busca de prevenir possíveis contaminações.

Assim, é essencial que a Administração Pública Municipal gerencie todo o processo de armazenamento dos resíduos produzidos nos ambientes hospitalares até a sua destinação final.

É importante atentar primeiramente às regras impostas para gestão adequada dos resíduos, como leis, regulamentos e decretos. Ainda, a política ambiental conta com uma série de Princípios Legais que são fundamentais para a orientação dos geradores desses resíduos.

Na maioria dos Municípios, o destino final dos resíduos de serviços de saúde (RSS) não são locais adequados, trazendo graves consequências 
para população. Ainda, na maioria das vezes, esse dano não é reparado por qualquer órgão competente.

O presente estudo tem por objetivo dissertar sobre a destinação dos RSS, a legislação vigente e o papel do gestor frente ao gerenciamento de resíduos gerados pela área de saúde na cidade de Prata, MG. Além disso, esclarecer sobre a responsabilidade civil do gerador do resíduo e da Administração Pública Municipal em todo o processo de gerenciamento, principalmente seu dever de armazenamento e transporte do RSS de forma adequada e segura até sua destinação final.

\section{FUNDAMENTAÇÃO TEÓRICA}

\subsection{Da responsabilidade objetiva do gerador de resíduos de serviços da saúde}

Fundamentada nos princípios de prevenção, precaução e responsabilização do gerador, a responsabilidade pelo correto gerenciamento dos RSS é do seu gerador, ou seja, dos estabelecimentos de serviços de saúde. Porém cabe aos órgãos públicos, no limite de suas competências, a regulamentação, gestão e fiscalização desses estabelecimentos. Nesse contexto, estamos diante do Princípio da Responsabilidade Compartilhada, pois tal responsabilidade se estende ao poder público e às empresas de coleta, tratamento e disposição final dos resíduos (RANGEL, 2014).

Dessa forma, considerando que o serviço de limpeza pública é um serviço público de interesse local, compete aos Municípios sua prestação, autorizada sua realização por meio de concessão ou permissão.

A RDC ANVISA n. 306/04 dedica um capítulo exclusivo para tratar sobre as competências e responsabilidades dos estabelecimentos de serviço de saúde geradores dos RSS (AGÊNCIA NACIONAL DE VIGILÂNCIA SANITÁRIA [ANVISA], 2004).

Conforme suas normas, primeiramente é necessário a elaboração do Plano de Gerenciamento de Resíduos de Serviços de Saúde por um responsável técnico designado, devendo esse plano obedecer à legislação ambiental, às normas de coleta e transporte dos resíduos, assim como todas as orientações do Regulamento. Posteriormente, deve-se capacitar e 
treinar todo o pessoal que atua direta ou indiretamente no gerenciamento de resíduos (ANVISA, 2004).

Considerando que é comum a terceirização de empresas especializadas no tratamento e disposição final dos resíduos de serviços de saúde, compete aos seus geradores requerer documento oficial que comprove o cadastro dessas terceirizadas no órgão responsável de limpeza urbana. Ainda, deve-se requerer dos órgãos públicos responsáveis pela execução da coleta até a disposição final, a comprovação de regulamentação conforme as orientações dos órgãos de meio ambiente (ANVISA, 2004).

Depreende-se da Resolução que existem inúmeras regras e normas a serem seguidas para adequação do gerenciamento dos RSS, portanto sua inobservância é passível de penalidade, surgindo a necessidade de responsabilizar o gerador de resíduos.

O Município de Prata, MG, objeto do presente estudo, apesar de não possuir uma legislação própria que responsabiliza os geradores dos RSS, possui Plano de Gerenciamento de Resíduos Sólidos específico, elaborado pelo Consórcio Público Intermunicipal de Desenvolvimento Sustentável do Triângulo Mineiro e Alto Paranaíba (CIDES) pelo qual o Município é consorciado, e planeja-se construir um aterro sanitário consorciado. Atualmente o consórcio procura alternativas de recursos para a construção desse aterro.

Considerando que tal medida levará certo tempo para sua total implantação (média de 18 meses), os Municípios consorciados buscam implantar medidas emergenciais para se adequarem à legislação. Nesse sentido, o Município de Prata está licenciando novas células para depósito de resíduos sólidos na área do Aterro Controlado (CIDES, 2017).

$E$, no que tange à responsabilidade do gerador de resíduos sólidos de serviços de saúde, a Administração Pública Municipal utiliza a teoria da responsabilidade objetiva, defendida pela Constituição Federal, Código Civil e Lei Federal 12.305/2010 (Política Nacional de Resíduos Sólidos) (BRASIL, 2010).

Ao mesmo tempo, o Município trata da matéria através do artigo 42, parágrafo único, Lei Complementar n. 004/2007, que institui o código de posturas do município de Prata e dá outras providências. E, a política ambiental do Município obedece tanto às normas desse código, como às nor- 
mas Estaduais e Federais, podendo "celebrar convênio com órgãos públicos Estaduais, Federais e particulares, para a execução de projetos ou atividades que objetivem o controle da degradação ambiental" (PRATA, 2007a).

O Código de Posturas Municipal estabelece, em seu artigo $9^{\circ}$, normas específicas de gerenciamento dos resíduos hospitalares, padronizando os procedimentos para acondicionamento dos RSS, prevendo que "Os resíduos hospitalares, provenientes de hospitais, ambulatórios, clínicas, laboratórios, farmácias e similares, deverão ser acondicionados em recipientes especiais, separados do lixo doméstico, conforme orientações da Vigilância Sanitária" (PRATA, 2007a).

Por seguinte, o parágrafo único do mesmo artigo dispõe sobre a frequência de coletas desses materiais nos estabelecimentos que produzem o material e o seu destino final, além das equipes técnicas responsáveis pela fiscalização e controle, prevendo que "A coleta dos resíduos hospitalares e congêneres será feita diariamente para incineração em local adequado, determinado pelo Departamento Municipal de Saúde, com supervisão e fiscalização pelo serviço de Vigilância Sanitária" (PRATA, 2007a).

A Lei Complementar Municipal n. 003/2007 traz um capítulo exclusivo que regulamenta sobre o Saneamento Ambiental e o manejo dos resíduos sólidos, visando promover a sustentabilidade ambiental do uso e da ocupação do solo (PRATA, 2007b).

Ressalta-se que referida Lei excepciona os resíduos sépticos provenientes de hospitais como um tema a ser tratado de forma especial no Código de Posturas, ou seja, é considerado de relevância e alta complexidade.

\section{METODOLOGIA}

\subsection{Abrangência}

O trabalho foi desenvolvido no município de Prata, Estado de Minas Gerais, nas onze unidades de saúde públicas existentes.

A pesquisa desenvolvida tem, como público-alvo, os funcionários dos serviços de saúde públicos, a rede privada, e a população para auxiliar na orientação quanto à necessidade de elaboração de PGRSS e da responsabilidade dos geradores de RSS, desde a sua produção até sua destinação final. 


\subsection{Prospecção bibliográfica}

Para condução do presente estudo e construção de um referencial teórico seguro, foi realizada uma revisão literária em doutrinas de autores renomados, legislação vigente, regulamentos, sites governamentais e artigos científicos sobre o tema. Ainda houve um levantamento das Leis Municipais que regem, de alguma forma, sobre os resíduos sólidos produzidos nos serviços de saúde.

A metodologia adotada efetivou-se através de pesquisas bibliográficas, leis, diretrizes em acervos digitais, baseando-se no método dogmático.

Foram destacadas as formas legais de manuseio e destinação do RSS, ressaltando as normas vigentes sobre a responsabilidade dos seus geradores e a preocupação primordial com a preservação ambiental para as presentes e futuras gerações.

\subsection{Levantamento de dados na Prefeitura Municipal de Prata, MG}

Foi realizado um levantamento de dados obtidos através de processos licitatórios ocorridos dentro da prefeitura para seleção de empresas terceirizadas que realizam serviços de recolhimento e destinação de resíduos hospitalares. Ainda, foi estudado o Plano de Gerenciamento de Resíduos Sólidos do Município e constatou-se que ele foi elaborado recentemente, em 2016, com o auxílio da Associação dos Municípios da Microrregião do Vale do Paranaíba (AMVAP). Trata-se de dados públicos cuja utilização, principalmente para fins de pesquisa científica, independem de prévia autorização.

\subsection{Levantamento de dados junto à empresa contratada}

Foram obtidos dados da empresa contratada relativos à quantidade, processo de recolhimento, manejo e destinação final dos resíduos de serviço de saúde recolhidos semanalmente nas Unidades de Saúde públicas de dezembro de 2017 a março de 2018. 


\subsection{Transcrição e tabulação dos dados}

Após obtenção das informações, estas foram transcritas e tabuladas em planilhas eletrônicas (software Excel) para posterior tratamento.

\subsection{Elaboração do Termo de Referência do processo licitatório}

Baseado nos resultados obtidos com o levantamento de dados e avaliação da legislação sobre o tema, e visando adequação às normas da Resolução RDC n. 306/2004 (ANVISA, 2004), foi desenvolvido um Termo de Referência para compor o processo licitatório de seleção de empresas para realização de limpeza pública em 2018. Tudo isto almejando colocar em prática a forma correta e segura de realizar o armazenamento, transporte e incineração dos resíduos dos serviços de saúde.

\subsection{Proposta para alteração da Lei Complementar n. 009/2009 (Código da Saúde)}

Em razão de a legislação municipal ser omissa sobre a responsabilização legal dos geradores de resíduos hospitalares, foi desenvolvido um texto referente a uma pequena alteração na legislação municipal Lei Complementar 009/2009 - denominado Código de Saúde, para dar mais clareza no sentido de que, se o gerador do resíduo de serviço de saúde não obedecer às normas legais de gerenciamento, responsabilizando-se por ele até a sua destinação final, poderá caracterizar a infração administrativa ambiental, independente de dolo ou culpa do agente.

\section{RESULTADOS E DISCUSSÃO}

A administração pública municipal está se atentando, de forma progressiva, para as questões ambientais, buscando estratégias e alternativas, inclusive através de regulamentação legal para alcançar o equilíbrio econômico sustentável. Diante disto, a presente pesquisa permitiu analisar os resultados da aplicação do Plano de Gerenciamento de Resíduos Sólidos no processo de gerenciamento de resíduos de serviços de saúde, sob os aspectos legais e ambientais. 


\subsection{Levantamento de dados na Prefeitura Municipal de Prata, MG}

Realizou-se levantamento de dados nos processos licitatórios para seleção de empresas terceirizadas atuantes na limpeza pública que realizam serviços de recolhimento e destinação de resíduos de serviços de saúde.

Foi cedido para análise o Plano de Gerenciamento de Resíduos Sólidos do Município; as Legislações Municipais que regulamentam sobre os resíduos, os processos licitatórios que objetivam a contratação de empresa especializada para execução dos serviços de limpeza pública (consistindo na coleta seletiva de resíduos, serviços especiais de limpeza urbana, caiação, remoção de entulho, poda de grama e manutenção de praças, operação do aterro controlado, coleta, transporte, tratamento e destinação final de resíduos sólidos de serviços de saúde-RSSS, operação e manutenção de usina de triagem e compostagem; coleta e transporte regular de resíduos sólidos domiciliares e comerciais com utilização de caminhões compactadores e varrição mecanizada de vias); os contratos de prestação de serviços dessas empresas; e as licenças ambientais adquiridas para a realização do serviço de coleta e incineração.

Após a análise de toda documentação, foi possível constatar a necessidade de praticar educação ambiental no sentido de auxiliar as pessoas atuantes na área da saúde a obedecer às regras impostas pela RDC 306/04 no gerenciamento dos resíduos da saúde (ANVISA, 2004). Ato contínuo, conforme exigências do Regulamento é necessário que um Profissional Responsável fiscalize constantemente se o Plano de Gerenciamento de Resíduos Sólidos de Saúde é utilizado na prática diária, dentro das unidades de saúde, inclusive sendo atualizado conforme a realidade da unidade.

Conforme a Lei Complementar n. 009, de 17 de dezembro de 2009, que institui o Código de Saúde do Município de Prata, o Setor de Vigilância Sanitária do Departamento Municipal de Saúde, tem por fim a promoção e execução de normas para o controle e fiscalização do resíduo doméstico e resíduos de serviços de saúde (RSS) (PRATA, 2009).

No artigo 66, são estipuladas as formas devidas no gerenciamento dos RSS, quais sejam: 
[...] acondicionamento em sacos plásticos branco leitoso, e separados dos materiais perfurocortantes, os quais deverão ser colocados em recipientes rígidos antes de serem acondicionados em sacos plásticos, e colocados em local apropriado, dentro do estabelecimento de saúde, não podendo, em hipótese alguma, serem mantidos nas calçadas, até que o serviço público especial o recolha. Parágrafo único - Os RSS terão coleta separada dos resíduos domiciliares e, com destinação final adequada, de modo a não apresentar riscos de proliferação de agentes patógenos e de contaminação ambiental. (PRATA, 2009).

No entanto notou-se uma falha na elaboração da citada Lei, considerando que ficaram lacunas ao não regulamentar sobre a Responsabilidade do gerador de resíduos e as consequências, desde sua geração até seu destino final.

Constatou-se ainda falha na elaboração do Plano de Gerenciamento de Resíduos Sólidos Municipal, ocorrida em 2016, pois este também não regulamenta sobre a responsabilidade e aplicação de penas nos casos de mal gerenciamento dos resíduos.

Esse Plano de Gerenciamento apresenta semelhanças com o Plano de Gerenciamento de Resíduos do Município de Araporã, MG, no que tange principalmente à preocupação de estabelecer que os resíduos gerados em estabelecimentos prestadores de serviços de saúde devem ser gerenciados de maneira correta, de modo a garantir a qualidade da saúde coletiva e a preservação do meio ambiente, mas deixa a desejar quanto à regulamentação da responsabilidade do gerador de RSS (ARAPORÃ, 2015).

Entretanto observa-se que o Plano de Gerenciamento de Resíduos de Serviços de Saúde do Município de Guaranésia, MG, é bastante completo e satisfatório no que tange à regulamentação das responsabilidades dentro do PGRSS, como, por exemplo, o dever de comunicação ao responsável técnico qualquer desconformidade no local gerador de resíduos (GUARANÉSIA, 2015).

A Lei Municipal n. 004/2007 que institui o Código de Posturas no Município de Prata classifica os graus da penalidade das infrações ambientais (leve, média, grave, gravíssima), no entanto não estipula valores de penalidades administrativas, sendo que de acordo com o art.9o, é considerado 
gravíssimo o ato de acondicionamento inadequado de resíduos de origem hospitalar (PRATA, 2007a).

O Pronto Atendimento Municipal possui seu PGRS próprio, pois, quando se trata de unidade de urgência e emergência, é necessário se adequar às realidades locais. Ainda, é certo que o risco de contaminação nesses locais é maior, devido ao grande fluxo de pessoas diariamente. Já as oito Unidades Básicas de Saúde Familiar (UBSF) existentes possuem um PGRS padrão, pois se trata de atendimentos médicos de rotina.

\subsection{Levantamento de dados junto à empresa licitada}

As informações obtidas após a análise desses documentos mostram a importância e o dever de elaboração do PGRS para as unidades de saúde, conforme sua realidade de produção e armazenamento de resíduos sólidos.

A empresa terceirizada realiza o recolhimento dos resíduos sólidos da saúde de todas unidades existentes no Município, como as clínicas, pet shops, farmácias, APAE, Centro de atendimento psicossocial, entre outras. E ressalta-se que o Município não cobra taxa das empresas privadas para realização de tal serviço.

Por essa razão, foi providenciada uma reunião com estas visando a orientação e educação ambiental através da exposição da legislação municipal vigente, de acordo com a RDC 306/04 (ANVISA, 2004). Foi esclarecido também sobre a necessidade de elaboração/adequação do PGRSS, orientando os profissionais sobre a responsabilidade objetiva pelo gerenciamento dos RSS, desde a sua geração até sua destinação final, e que o planejamento do programa deve ser feito em conjunto com todos os setores, com as responsabilidades e obrigações de cada um definidas em relação aos riscos.

O Município de Canápolis, MG, localizado no Triangulo Mineiro, também possui um sistema de coleta semelhante ao Município em questão, pois foi constatado, em seu Plano de Saneamento, que os RSS possuem coleta diferenciada; os custos não são cobrados como taxa extra pela prefeitura; os resíduos são quantificados e a coleta e transporte realizado pela Prefeitura Municipal (CANÁPOLIS, 2015). 
A coleta dos RSS em Prata é realizada semanalmente, e todo material recolhido é transportado para o Município de Senador Canedo, no Estado de Goiás, local em que, através de uma empresa terceirizada, é realizada a incineração dos resíduos.

Os resíduos são descartados em recipientes conforme sua classe, para facilitar o processo de recolhimento, transporte e disposição final. Dessa forma, conforme estipulado na RDC 306/04 (ANVISA, 2004), o interior de cada sala é composto por sacos plásticos e recipientes resistentes, de forma que evitem vazamentos e resistam às ações de punctura e ruptura. Ainda, os recipientes possuem capacidade de acondicionamento compatível com a geração diária de cada tipo de resíduo.

Diferentemente, no Município de Canápolis, MG, seu Plano Municipal de Saneamento Básico não obedece às regras da Resolução CONAMA 358/2005 (BRASIL, 2005). A forma correta de acondicionamento dos resíduos perfuro cortantes é em recipientes de papelão, e os Grupos A, B e E devem ser acondicionados em saco branco leitoso. Ocorre que, no Município supracitado não foi identificado o acondicionamento e armazenamento dos resíduos de serviços de saúde em conformidade com a resolução. (CANÁPOLIS, 2015).

As Unidades de Saúde do Município têm adotado comportamento inadequado em relação ao descarte de resíduos líquidos, pois estes são dispensados em vaso sanitário, se tornando potenciais poluidores do solo.

Conforme Benine e Godoy (2018), para solucionar esse grave problema gerado pela disposição inadequada de resíduos líquidos, deve-se construir, nos estabelecimentos de saúde, uma rede de tratamento de efluentes. Tal acondicionamento correto dos resíduos é de extrema importância para a segurança dos trabalhadores, além de facilitar a coleta e transporte.

Posteriormente, todos os recipientes com o material descartado passam por processo de segregação, ou seja, são separados conforme suas características físicas, químicas e biológicas.

Em seguida, são armazenados em um local externo e de fácil acesso das unidades de saúde, para que sejam recolhidos e transportados para o local da disposição final. 
Os RSS são recolhidos semanalmente, em horários preestabelecidos no PGRSS das unidades de saúde, por um profissional devidamente equipado com EPI (equipamento de proteção individual), e sua pesagem é realizada no momento do recolhimento. Porém a forma correta de armazenamento temporário é a refrigeração dos resíduos de fácil putrefação quando coletados por período superior a 24 horas de seu armazenamento (FUNDAÇÃO OSWALDO CRUZ [FIOCRUZ], s.d.).

Um detalhe importante a salientar é que foi possível identificar a inexistência de carrinhos coletores para o transporte de RSS dentro das unidades de saúde, o que pode gerar riscos à saúde dos trabalhadores que o manuseiam.

Juntamente à empresa licitada, foi realizado um levantamento de dados referentes à pesagem (em quilogramas) semanal dos resíduos de serviços de saúde gerados em cada unidade de saúde pública municipal, dos meses de dezembro de 2017 a março de 2018 (Tabela 1).

Tabela 1 - Coleta de resíduos hospitalares nas Unidades de saúde do Município de Prata, MG, de dezembro de 2017 a março de 2018

\begin{tabular}{c|c|c|c|c|c}
\hline Estabelecimento & Dezembro & Janeiro & Fevereiro & Março & Total \\
\hline Hospital da Mulher & $11,9 \mathrm{~kg}$ & $30,8 \mathrm{~kg}$ & $14,8 \mathrm{~kg}$ & $29 \mathrm{~kg}$ & $86,5 \mathrm{~kg}$ \\
\hline $\begin{array}{c}\text { Hospital e } \\
\text { Maternidade } \\
\text { Renascer }\end{array}$ & $10,6 \mathrm{~kg}$ & $138,4 \mathrm{~kg}$ & $70 \mathrm{~kg}$ & $254 \mathrm{~kg}$ & $473 \mathrm{~kg}$ \\
\hline $\begin{array}{c}\text { PAM (Pronto } \\
\text { atendimento } \\
\text { Municipal) }\end{array}$ & $25,5 \mathrm{~kg}$ & $265 \mathrm{~kg}$ & $125 \mathrm{~kg}$ & $303 \mathrm{~kg}$ & $718,5 \mathrm{~kg}$ \\
\hline $\begin{array}{c}\text { Posto de Saúde } \\
\text { Primavera }\end{array}$ & $15,6 \mathrm{~kg}$ & $32,2 \mathrm{~kg}$ & $28,2 \mathrm{~kg}$ & $20,6 \mathrm{~kg}$ & $96,6 \mathrm{~kg}$ \\
\hline PSF Bela Vista & $24,9 \mathrm{~kg}$ & $16,5 \mathrm{~kg}$ & $12,5 \mathrm{~kg}$ & $27,6 \mathrm{~kg}$ & $81,5 \mathrm{~kg}$ \\
\hline $\begin{array}{c}\text { PSF Colina Park } \\
\text { Boulevar }\end{array}$ & $15,5 \mathrm{~kg}$ & $16,7 \mathrm{~kg}$ & $11,7 \mathrm{~kg}$ & $32,8 \mathrm{~kg}$ & $76,7 \mathrm{~kg}$ \\
\hline PSF Cruzeiro do Sul & $19,1 \mathrm{~kg}$ & $17,3 \mathrm{~kg}$ & $9,8 \mathrm{~kg}$ & $18,6 \mathrm{~kg}$ & $64,8 \mathrm{~kg}$ \\
\hline PSF Dona Regina & $10,1 \mathrm{~kg}$ & $35,3 \mathrm{~kg}$ & $21,2 \mathrm{~kg}$ & $25,2 \mathrm{~kg}$ & $91,8 \mathrm{~kg}$ \\
\hline PSF Esperança & $19,3 \mathrm{~kg}$ & $18,2 \mathrm{~kg}$ & $3 \mathrm{~kg}$ & $10,4 \mathrm{~kg}$ & $50,9 \mathrm{~kg}$ \\
\hline PSF Oliveira & $33,7 \mathrm{~kg}$ & $46,7 \mathrm{~kg}$ & $33,5 \mathrm{~kg}$ & $41,3 \mathrm{~kg}$ & $155,2 \mathrm{~kg}$ \\
\hline PSF Progresso & $4,5 \mathrm{~kg}$ & $4,4 \mathrm{~kg}$ & $2,6 \mathrm{~kg}$ & $5,4 \mathrm{~kg}$ & $16,9 \mathrm{~kg}$ \\
\hline Total & $190,7 \mathrm{~kg}$ & $621,5 \mathrm{~kg}$ & $332,3 \mathrm{~kg}$ & $767,9 \mathrm{~kg}$ & $\mathbf{1 . 9 1 2 , 4 ~ k g}$ \\
\hline
\end{tabular}

Fonte: Próprios autores. 
Constatou-se que a quantidade de resíduos de serviços de saúde produzidas nas unidades de saúde públicas do Município é relativamente pequena.

Somente o Hospital e Maternidade Renascer e o Pronto Atendimento Municipal produzem maiores quantidades semanalmente. A UBSF do bairro Oliveira é a que mais produz RSS em comparação às demais, devido ao fato de ser a unidade maior e mais movimentada.

No que tange aos meses em que foi realizada a pesquisa, analisando a quantidade total de RSS produzida nas unidades de saúde, é notório que o mês de dezembro apresentou uma quantidade bastante inferior em relação aos demais. Conforme relatos dos profissionais da área de saúde, isto se deve ao fato de ser um mês de férias, em que a população do Município viaja e, consequentemente, diminui a procura por tratamentos de saúde.

Após levantamento de dados, nota-se que, em apenas quatro meses, foram produzidos aproximadamente dois mil quilos de RSS, média de 500 kg mensais, apenas nas onze unidades de saúde públicas do Município, mas não só as unidades públicas de saúde produzem esse material. Os RSS são produzidos também em farmácias, clínicas odontológicas e veterinárias, assistência domiciliar, necrotérios, instituições de cuidado para idosos, hemocentros, laboratórios clínicos e de pesquisa, instituições de ensino na área da saúde (GARCIA; ZANETTI-RAMOS, 2004). Neste trabalho, não foram coletados dados nesses locais, por isso acredita-se que a produção de RSS no Município mensalmente seja bem maior.

Diante disto é possível imaginar a gravidade do problema ambiental e de saúde pública se este resíduo fosse descartado de forma inadequada, pois este material é fonte potencial de propagação de doenças, provocam risco adicional aos trabalhadores dos serviços de saúde e a comunidade, além de causar sérios danos ao meio ambiente (SILVA; HOPPE, 2005).

\subsection{Avaliação da possibilidade de imposição de multas nas unidades privadas}

Com os dados já tabulados, foi constatado que unidades de saúde privadas existentes no Município não providenciaram a obrigatória elabo- 
ração do Plano de Gerenciamento dos resíduos e que seus resíduos são recolhidos pela empresa licitada. Diante disto, seus proprietários foram convocados pelo departamento jurídico da Prefeitura para uma reunião visando orientá-los, e deu-se um prazo de três meses para regularizarem seus PGRS conforme a realidade de suas unidades, sob pena de multa

Ainda, foram notificados da necessidade de cumprir as normas legais de gerenciarem seus resíduos, sendo responsáveis desde a sua geração até a sua destinação final. Conforme exposto na fundamentação desta pesquisa, tal responsabilidade é regulamentada pela Constituição Federal/1988, Código Civil/2002, RDC ANVISA 306/04 e Resolução do CONAMA n. 316/2002 (BRASIL, 2016; BRASIL, 2002; ANVISA, 2004).

\subsection{Elaboração do Termo de Referência do processo licitatório}

Houve uma melhoria na elaboração do Termo de Referência do edital do processo licitatório de limpeza pública do ano de 2018, orientando as empresas credenciadas e vencedoras sobre a forma correta e segura de realização do transporte, armazenamento e incineração dos resíduos dos serviços de saúde, e consequentemente, colaborou-se para a redução de acidentes decorrentes do mal gerenciamento desses resíduos.

Apesar do atual entendimento do Tribunal de Contas no que tange à necessidade de abrir processo licitatório individual para contratação de empresas que realizam coleta de RSS, o Município utiliza somente de uma licitação para limpeza pública, abrangendo todos tipos de resíduos.

Diante disto, após tentativas frustradas de individualizar tal licitação, visando adequar o edital em andamento, foi necessário explicitar algumas normas e procedimentos a serem seguidos na elaboração do Termo de Referência que compõe o edital do processo licitatório n. 013/2018, Concorrência Pública n. 001/2018 de limpeza pública em andamento na Administração Pública Municipal em estudo, sendo importante elaborar um tópico exclusivo para o tema "Coleta, tratamento e disposição final de resíduos de saúde". 


\subsection{Proposta de alteração da Lei Complementar n. 009/2009 (Código da Saúde)}

É certo que a responsabilidade pelo gerenciamento dos RSS não é exclusiva dos estabelecimentos geradores, e sim de toda a sociedade, que possui o dever de cobrar e sensibilizar uns aos outros (CAMARGO et al., 2009).

Espera-se ainda que "os resíduos coletados nos municípios recebam tratamento e disposição final como preconizam as normatizações, já que os problemas ambientais gerados pelo indevido gerenciamento interferem na saúde dos seres humanos" (CEZAR-VAZ et al., 2005).

Ademais há que se considerar que a ocorrência da situação prevista em norma como infração ambiental deve ser penalizada, independentemente de haver dolo ou culpa do agente infrator, ou seja, a responsabilidade é considerada objetiva.

Dessa forma, para evitar tais ilegalidades, este trabalho aconselha uma nova regulamentação da Administração Pública na legislação municipal existente, qual seja LC 009/2009, para normatizar a responsabilidade do agente causador do dano ambiental específico do gerenciamento de resíduos sólidos de serviços de saúde, visando responsabilizá-lo pelo correto gerenciamento desses resíduos e fiscalização de sua destinação final, sob pena de aplicação de multas.

Ainda, a legislação ressalta a responsabilidade compartilhada e solidária da Administração Pública, caso não haja fiscalização da sua aplicabilidade e eficiência. Portanto, se o Município gestor não fiscalizar devidamente, se tornará responsável. Trata-se da prática moderna de "Gestores Sustentáveis".

Referida Lei Municipal em seu artigo 60, IX, responsabiliza o setor de Vigilância Sanitária do Departamento Municipal de Saúde pelo controle e fiscalização dos serviços de saúde, especialmente dos resíduos de serviços de saúde (PRATA, 2009).

Entretanto não reservou um capítulo exclusivo para regulamentar a responsabilidade objetiva pelo gerenciamento desses resíduos, conforme legislação federal já detalhada anteriormente. 
No artigo 143 da Lei 009/2009, ao estabelecer as infrações e penalidades, não reservou um inciso específico para responsabilizar o gerador dos RSS, advertindo no inciso XXXII sobre a responsabilidade pelos resíduos de maneira geral.

Por essa razão, tomando-se como exemplo a Lei n. 4869, de 26 de dezembro de 2017 (OSASCO, 2017), foi elaborada uma proposta de lei visando alterar a legislação 009/2009, incluindo um artigo específico que regulamenta sobre a responsabilidade dos geradores de resíduos de serviços de saúde.

\section{CONSIDERAÇÕES FINAIS}

Com a conclusão desta pesquisa, foi possível notar a importância de adequação do PGRSS das unidades de saúde públicas e privadas para dar efetividade às normas legais no município de estudo.

Dessa forma, a orientação aos profissionais da área de saúde sobre a necessidade de atualização e adequação dos seus Planos conforme a realidade da unidade de saúde do município é fundamental para a regularização da coleta dos resíduos de serviços de saúde.

Há a necessidade de regulamentar, através de legislação municipal de Prata, MG, sobre a responsabilidade dos geradores de Resíduos de Serviços de Saúde, bem como aos seus representantes legais pelo gerenciamento desses resíduos, desde a sua geração até a disposição final, incluindo o financiamento dos custos desse processo, de forma a atender aos requisitos ambientais de saúde pública e saúde ocupacional. Se não cumprir esses requisitos, o gerador pode ser penalizado com a aplicação de multas.

A aprovação desta proposta proporcionará maior segurança jurídica para a Prefeitura, profissionais da área da saúde e população do município de Prata, MG. 


\section{REFERÊNCIAS}

ANVISA. Resolução RDC n. 306, de 7 de dezembro de 2004. Dispõe sobre o regulamento técnico para o gerenciamento de resíduos de serviços de saúde. Disponível em http://portal.anvisa.gov.br/documents/33880/2568070/ res0306_07_12_2004.pdf/95eac678-d441-4033-a5ab-f0276d56aaa6. Acesso em: 21 maio 2018.

ARAPORÃ (Município do Estado de Minas Gerais). Plano Municipal de Saneamento Básico de Araporã-MG. 2015. Disponível em: http://cides.com.br/wp-content/ uploads/2016/04/PMSB-Arapor\%C3\%A3-FINAL.compressed.pdf. Acesso em: 14 maio 2018.

BENINI, S. M.; GODOY, J. A. R. A questão ambiental em debate: pesquisas e práticas. 2. ed. Tupã, SP: ANAP, 2018.

BRASIL. Constituição da República Federativa do Brasil de 1988. Brasília, DF: Presidência da República, [2016]. Disponível em: http://www.planalto.gov.br/ ccivil_03/constituicao/constituicao.htm. Acesso em: 13 nov. 2017.

BRASIL. Lei n. 12.305, de 2 de agosto de 2010. Institui a Política Nacional de Resíduos Sólidos; altera a Lei n 9.605, de 12 de fevereiro de 1998; e dá outras providências. Disponível em: http://www.mma.gov.br/port/conama/legiabre.cfm?codlegi=636. Acesso em: 18 set. 2017.

BRASIL. Ministério do Meio Ambiente. Conselho Nacional do Meio Ambiente - CONAMA. Resolução n. 358, de 29 de abril de 2005. Disponível em: http:// www2.mma.gov.br/port/conama/legiabre.cfm?codlegi=462. Acesso em: 8 ago. 2017.

BRASIL. Ministério do Meio Ambiente. Conselho Nacional do Meio Ambiente CONAMA. Resolução n. 316, de 29 de outubro de 2002. Disponível em: http:// www2.mma.gov.br/port/conama/legiabre.cfm?codlegi=338. Acesso em: 8 ago. 2017.

CAMARGO, M. E.; MOTTA, M. E. V.; LUNELLI, M. O.; SEVERO, E. A. Resíduos sólidos de serviços de saúde: um estudo sobre o gerenciamento. Scientia Plena, Aracaju, SE, v. 5, n. 7, p. 1-15, 2009.

CANÁPOLIS (Município do Estado de Minas Gerais). Plano Municipal de Saneamento Básico. Canápolis, MG, 2015. Disponível em: http://cides.com.br/wp-content/ 
uploads/2016/04/PMSB-Can\%C3\%A1polis-FINAL.compressed.pdf. Acesso em: 12 maio 2018.

CEZAR-VAZ, M. R. et al. Saber Ambiental: instrumento interdisciplinar para a produção de saúde. Texto \& Contexto - Enfermagem, Florianópolis, SC, v. 14, n. 13, p. 391-7, jul./set. 2005.

CIDES. Informações sobre a gestão dos resíduos sólidos de serviços de saúde RSSS no municipio de Prata - MG. 2016. Disponível em: http://cides.com.br/pages/ MedidasEmergenciais/MEDIDAS\%20EMERGENCIAIS\%20-\%20PRATA/RSSS\%20 PRATA\%20FORMATADO.compressed.pdf. Acesso em: 25 jun. 2018.

FIOCRUZ. Gerenciamento dos Resíduos de Serviço de Saúde. [s.d.]. Disponível em: http://www.fiocruz.br/biosseguranca/Bis/lab_virtual/gerenciamento-residuosservico-saude.htm. Acesso em 28 ago. 2018.

GARCIA, L. P.; ZANETTI-RAMOS, B. G. Gerenciamento dos resíduos de serviços de saúde: uma questão de biossegurança. Cadernos de Saúde Pública, Rio de Janeiro, v. 20, n. 3, p. 744-52, maio/jun. 2004.

GUARANÉSIA (Município do Estado de Minas Gerais). Plano de Gerenciamento dos Resíduos de Serviços de Saúde. Pronto Atendimento Municipal Guaranésia/MG, 2015. Disponível em: http://www.prefguaranesia.mg.gov.br/ editais/2015/29-05-2015/4\%20-\%20PGRS\%20SAUDE\%20-\%20PRONTO\%20 ATENDIMENTO\%20MUNICIPAL.pdf. Acesso em: 12 maio 2018.

OSASCO. SÃO PAULO. Lei n. 4869, de 26 de dezembro de 2017. Disponível em: https://leismunicipais.com.br/a/sp/o/osasco/lei-ordinaria/2017/487/4869/ lei-ordinaria-n-4869-2017-institui-o-sistema-integrado-de-manejo-e-gestao-deresiduos-de-servicos-de-saude. Acesso em: 3 maio 2018.

PRATA (Município do Estado de Minas Gerais). Lei Complementar Municipal n. 004, de 18 de outubro de 2007. Institui o código de posturas do Município de Prata, MG. Prata, MG, 2007a.

PRATA (Município do Estado de Minas Gerais). Lei Complementar Municipal n. 003, de 13 de julho de 2007. Plano Diretor Participativo de Prata, MG. Prata, MG, 2007b.

PRATA (Município do Estado de Minas Gerais). Lei Complementar n. 009, de 17 de dezembro de 2009. Institui o Código de Saúde do Município de Prata, MG, 2009. 
RANGEL, T. L. V. Aspectos gerais à política nacional de resíduos sólidos. Âmbito Jurídico, Rio Grande, XVII, n. 123, abr. 2014. Disponível em: http://www.ambitojuridico.com.br/site/?n_link=revista_artigos_leitura\&artigo_id=14634. Acesso em: 15 fev. 2018.

SILVA, C. F.; HOPPE, A. E. Diagnóstico dos Resíduos de Serviços de Saúde no interior do Rio Grande do Sul. Engenharia Sanitária e Ambiental, Rio de Janeiro, v. 10, n. 2, p. 146-51, abr./jun. 2005. 